\title{
The Effect of Road Shoulder and Weather Conditions on the Occurrence of Rollover Crashes in Two-lane Highways
}

\author{
Ali Abdi Kordani', Bahram Shirini ${ }^{1 *}$, Mirbahador Yazdani ${ }^{1}$ \\ 1 Department of Civil Engineering - Transportation, Faculty of Technical \& Engineering, Imam Khomeini International University, \\ Imam Khomeini Blvd, Postal Code: 34148 - 96818, Qazvin, Iran \\ * Corresponding author, e-mail: b.shirini@edu.ikiu.ac.ir
}

Received: 28 May 2018, Accepted: 09 September 2019, Published online: 15 October 2019

\begin{abstract}
Rollover crash is a type of dangerous crash that occurs often in two-lane highways. Therefore, this study evaluates the effect of road shoulder and weather condition on rollover crashes. Crash data show that 8,609 crashes were recorded from 2006 to 2009 on six two-lane highways located at the center of Iran. This data contains 1860 rollover crashes. Rollover crash in this paper not included the head on crashes and fixed object crashes. Therefore the rollover crashes are only single vehicle crashes. Binary logit was selected for modelling since there were two possible outcomes: rollover crashes and other crash types. The variables of the final model include highway class, road shoulder width, as well as rainy, snowy, foggy and night conditions. The modeling results show that rainy and foggy variables, with coefficients of 0.731 and 0.719 respectively, had the greatest effects on rollover crash occurrence. Also, road shoulder width and night conditions, with coefficients of 0.221 and 0.184 respectively, had the least effects on rollover crash occurrence. Afterward, sensitivity analysis was performed on all the independent variables, and the results show variable variation and indicate that the probability of rollover crash occurrence is $21.29 \%$ on the mentioned highway.
\end{abstract}

Keywords

road shoulder, weather condition, rollover crash, binary logit

\section{Introduction}

Rollover crash is a dangerous type of crash that is common in two-lane highways. Therefore, this study evaluates the effect of road shoulder and weather conditions on rollover crashes.

A large number of studies have applied ordered response Logit/Probit models to examine significant correlation of roadway geometrics, human factors, vehicle attributes and environmental effects with crashes [1-4]. Yazdani and Nassiri [5] investigated the effect of weather on the severity of multi-vehicle crashes by using logit models. Results indicated that the probability of occurrence of the damage only crash is $77.5 \%$, while the probability of occurrence of injury and fatal crashes are $18.9 \%$ and $3.6 \%$, respectively. Jafri and Hadji [6] used ordered-probit model to analysis of the injury severity of crashes in three lighting conditions. Schneider et al. [7] involved the development of multinomial logit models to assess driver injury severity resulting from single-vehicle crashes on such roads. Chen et al. [8] used ordered logit model to examine the significant factors in predicting driver injury severities in rural non-interstate crashes. Results indicate that the model employed in this study outperforms ordinary ordered logit model in model fit and parameter estimation.

Young and Liesman [9] employed quantitative models to estimate the relationship between wind speed and truck overturning. They obtained meteorological databases from 21 weather stations near Wyoming and employed a crash database consisting of 14,700 truck crashes from 1994 to 2003. Also, they used a binary logit model to estimate the relationship between wind speed and truck overturning. Their results indicate that wind speed and truck overturning have a significant correlation. Farmer and Adrian [10] studied the effect of environmental factors on passenger-car and light-truck crashes as well as crash severity. Out of 78,000 single-vehicle crashes that occurred from 1995 to 1998, more than 14,000 were fatal crashes. Their results show that rollover crash was high among young drivers and in rural curves. After considering the effect of driver's age, driver's gender, roadway alignment and surface condition, it was discovered that light trucks were involved in rollover crashes more than passenger cars. 
Zegeer and Deacon [11] investigated the effect of lane width, shoulder width and shoulder type on highway safety. Their investigation was based on literature and development models and aimed to determine the factors affecting vehicle crashes on two-lane highways. Harwood et al. [12] proposed an algorithm for predicting the safety performance of two-lane highways. The crash prediction algorithm contains base models and crash modification factors. The base models provide an estimate of the safety performance of a road or intersection at base conditions. The crash modification factors involve the lane width, shoulder width, shoulder type, horizontal curves, grades, road density, two-way leftturn lanes, passing lanes, roadside design for highways and deviation angle, traffic control, individual left- and rightturn lanes, sight distance, and straight line for intersections. Potts et al. [13] investigated the relationship between lane width and road safety. Their results indicate that reducing the lane width of urban and suburban road below $3.65 \mathrm{~m}$ increased crash frequency. Their paper suggests geometric design policies in the use of lane width less than $3.65 \mathrm{~m}$. Lee et al. [14] investigated the effect of lane width on crash rate. They suggested a nonlinear relationship between crash rate and lane width. The research used geometric and crash data of Florida covering three years. Their results indicate that the crash rate on a lane width of $12 \mathrm{ft}$ is highest, while those on lane widths less and more than $12 \mathrm{ft}$ are lower. The effect changes with speed. Zegeer et al. [15] investigated the effect of lane width and shoulder type on crash rate with respect to two-lane rural roads. In their research, three types of crashes were studied (run-off-road, head-on, and sideswipe crashes). A crash rate reduction of up to $39 \%$ was recorded on roads with $3.35 \mathrm{~m}$ lane width compared with those of $2.13 \mathrm{~m}$ lane width. Similarly, a reduction of $21 \%$ was observed on roads with $2.74 \mathrm{~m}$ shoulder compared with those without shoulder. In the study, the presence of horizontal curves, vertical curves and speed variation were not considered. Another study was performed by Zegeer et al. [16] on the effect of lane and shoulder widths on safety. The research used a multiplicative crash prediction model which considered ADT, lane width, paved and unpaved shoulder width, and road side rating as well as focused on related crash types. The results show crash rate reduction of up to $40 \%$ for $1.22 \mathrm{~m}$ lane widening and $49 \%$ reduction for $2.44 \mathrm{~m}$ shoulder widening.

Gross and Jovanis [17] investigated the effect of lane and shoulder widths on safety by using the case-control method. The geometric, traffic and crash data used in their study were for rural two-lane undivided highway segments collected over some years, from 1997 to 2001. Logistic regression models were used to estimate the odds ratio for lane and shoulder widths separately. The study discussed the strengths and weaknesses of this method compared with CMFs. Usually, statistical models are used to estimate the impact of shoulder and lane widths on safety. However, in a study by Jovanis and Gross [18], two unique approaches, the case-control and cohort methods, were used in the design. In highway safety, the case-control and cohort methods indicate the potential to relate geometric and traffic characteristics to crashes. The geometric, traffic and crash data were those of two-lane roads in Pennsylvania. Logistic regression models were used to estimate the odds ratio for lane and shoulder widths, while Cox risk models were used to estimate the relative risk. These methods showed that crash frequency was reduced with increasing shoulder width. Gross and Donnell [19] used two methods to determine crash modification factors (CMFs). Their study utilized case-control and cross-sectional analyses to calculate CMFs for fixed roadway lighting and allocation of lane and shoulder widths. The results indicate that based on the case-control method, the CMF for intersection lighting was 0.886 , while for the cross-sectional method, the CMF was 0.881. Wood et al. [20] collected crash data for ten years on urban arterial roads located in four cities in Nebraska and evaluated the crash modification factors (CMFs) for various lane widths and crash types. To estimate CMF, negative binomial method or Poisson regression was used. The lane widths used in their study were 9 , 10,11 , and $12 \mathrm{ft}$. Roads with lane widths of 10 and $9 \mathrm{ft}$ had the highest and lowest crash frequency respectively.

Roque et al. [21] investigated run-off-road (ROR) crash severity. ROR crash data were accumulated on freeway road sections in Portugal, and multinomial and mixed logit models were used to evaluate the severity. The results show that the critical side slope on the recoverable area of the road plays an important role in reducing ROR crash severity. Roy and Dissanayake [22] have studied effective variables contributory cause run-off-road (ROR) and non-run-off-road (NROR) crashes. They found that parameters like Nighttime, weekends, adverse weather, rural area, gravel and curved roads, higher speed limits, wet and icy road surface, and utility vehicles are the ordinary characteristics of ROR crashes. Qiong Wu et al. [23] have investigated the effectiveness of parameters like gender, road surface condition and alcohol Influenced on single-vehicle rollover crashes. In this study, a mixed logit model is developed to identify the heterogeneous impacts of gender-interpreted on rollover crashes. 


\section{Data collection}

In this study, the crash data of six two-lane highways located at the center of Iran were selected for analysis. These highways, with approximately 2,000 crashes per year, are considered as highways with higher crash number. The study area is shown in Fig. 1. Table 1 introduces these highways and their characteristics, such as highway class, traffic volume, highway length, maximum speed limit and roadway equipment.

In Table 1 highways are classified in two classes, Class I is highways where drivers expect to travel at relatively high speeds, such as major intercity routes, primary connectors of major cities, daily commuter routes and Class II is highways where drivers do not necessarily expect to travel at high speeds, such as access routes to Class I facilities, connectors of small cities with low traffic volume. The crash data include 8,609 crashes recorded from 2006 to 2009. The crash types include single- and multi-vehicle crashes. The type of single-vehicle crash considered is rollover crash. This dataset contains 1,860 rollover crashes. Initial crash data includes head of crash with rollover, head of crash without rollover, rear of crash, collision with roadside vertical panels, colliding with pedestrian, ran-off-road

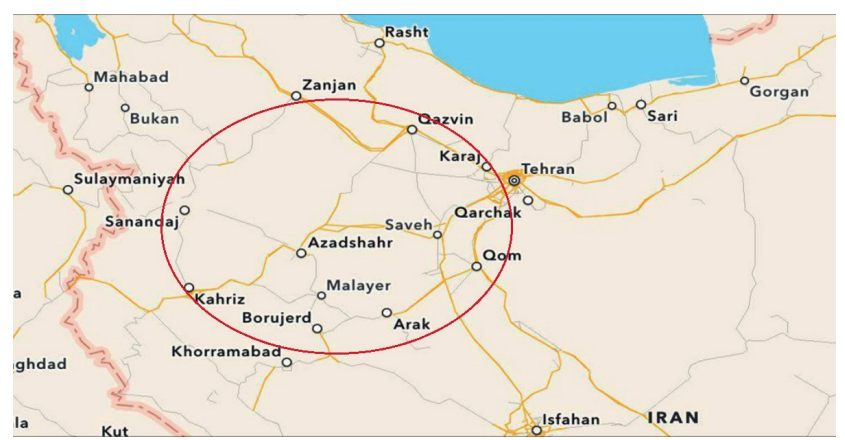

Fig. 1 Study area

with rollover and ran-off-road without rollover. In other words, ran-off-road with rollover crashes were filtered and selected between the above-mentioned crashes so the rollover crashes incorporate only single vehicle crashes. Other crash details are weather condition, type of road shoulder and road shoulder width. The model consists of eight independent variables and one dependent variable (crash type).

Table 2 shows these variables along with their category coding and summary statistics. In this table, dummy variable of weather condition is "dry weather" variable. Dry weather contains the clear weather and cloudy weather. In this weather road surface is completely dry. For example in

Table 1 Introduction of studied roads

\begin{tabular}{lcccc}
\hline Road name & $\begin{array}{c}\text { Traffic volume } \\
(\mathrm{veh} / \text { day })\end{array}$ & $\begin{array}{c}\text { Road Length } \\
(\mathrm{km})\end{array}$ & $\begin{array}{c}\text { Highway } \\
\text { class }\end{array}$ & Road equipment \\
\hline Saveh-Tehran & 17000 & 130 & Class I & No lighting system, No Guard rail, 1 lane in each direction \\
Saveh-Hamedan & 14000 & 185 & Class I & No lighting system, No Guard rail, 1 lane in each direction \\
Arak-Borujerd & 15,000 & 115 & Class I & No lighting system, No Guard rail, 1 lane in each direction \\
Arak-Khomein & 8,000 & 65 & Class II & No lighting system, No Guard rail, 1 lane in each direction \\
Arak-Farmahin & 6,000 & 50 & Class II & No lighting system, No Guard rail, 1 lane in each direction \\
Khomein-Delijan & 9,000 & 75 & Class II & No lighting system, No Guard rail, 1 lane in each direction \\
\hline
\end{tabular}

Table 2 Variables used in the model

\begin{tabular}{|c|c|c|c|c|c|c|}
\hline Variable & Minimum & Maximum & Mean & $\begin{array}{l}\text { Standard } \\
\text { deviation }\end{array}$ & Category coding & Proportion of crashes occurring \\
\hline Crash type & 0 & 1 & - & - & Rollover $=1$, other $\operatorname{crash}=0$ & $\begin{array}{c}\text { Rollover }=21.6 \%, \\
\text { other crash }=78.4 \%\end{array}$ \\
\hline Highway class & 0 & 1 & - & - & Class $\mathrm{I}=1$, Class $\mathrm{II}=0$ & Class I $=67.9 \%$, Class II $=32.1 \%$ \\
\hline Road shoulder width (m) & 0 & 4 & 1.550 & 0.499 & - & - \\
\hline Soil road shoulder ${ }^{\mathrm{a}}$ & 0 & 1 & - & - & Soil road shoulder $=1$, others $=0$ & $\begin{array}{c}\text { Soil road shoulder }=41.6 \% \text {, } \\
\text { others }=58.4 \%\end{array}$ \\
\hline Asphalt road shoulder ${ }^{\mathrm{a}}$ & 0 & 1 & - & - & $\begin{array}{l}\text { Asphalt road shoulder }=1, \\
\text { others }=0\end{array}$ & $\begin{array}{c}\text { Asphalt road shoulder }=9.3 \%, \\
\text { others }=90.7 \%\end{array}$ \\
\hline Rainy $^{\mathrm{b}}$ & 0 & 1 & - & - & Rainy $=1$, others $=0$ & Rainy $=2.9 \%$, others $=97.1 \%$ \\
\hline Snowy ${ }^{b}$ & 0 & 1 & - & - & Snowy $=1$, others $=0$ & Snowy $=4 \%$, others $=96 \%$ \\
\hline Foggy $^{b}$ & 0 & 1 & - & - & Foggy $=1$, others $=0$ & Foggy $=0.8 \%$, others $=99.2 \%$ \\
\hline Night condition & 0 & 1 & - & - & Night $=1$, day $=0$ & Night $=28.6 \%$, day $=71.4 \%$ \\
\hline
\end{tabular}

a Dummy variable compared with the "without acceptable road shoulder" variable.

${ }^{\mathrm{b}}$ Dummy variable compared with the "dry weather" variable. 
this category rainy variable is compared with other variables such as "Snowy", "Foggy", "Clear weather" and "Cloudy weather"; Or snowy variable is compared with other variables that in this case other include "Rainy", "Foggy", "Clear weather" and "Cloudy weather". Dummy variable of road shoulder types is 'without acceptable road shoulder width' variable. The acceptable road shoulder width is more than 0.5 meter.

\section{Methodology}

Binary models are appropriate when the response takes one of only two possible values representing success and failure. Binary logit is one of the discrete choice models that contain two options. In binary logit, the stochastic components of the utility error have a similar and independent gumbel distribution [24]. In this study, a binary logit model was used since there were two possible outcomes, rollover crashes or other crash types. Also, the stochastic components follow the logistics distribution. Eq. (1) shows the stochastic components of the utility error in binary model. Also, in Eq. (2), the general form of binary logit is shown.

$$
\begin{aligned}
& P_{i}=P_{r}\left(U_{i}>U_{J}\right)=P_{r}\left(V_{i}+\varepsilon_{i}>V_{j}+\varepsilon_{j}\right) \\
& =P_{r}\left(\varepsilon_{j}-\varepsilon_{i}<V_{i}-V_{j}\right), \\
& P_{i}=P_{r}\left(\varepsilon^{*}>V_{i}-V_{j}\right)=\frac{e^{V_{i}}}{e^{V_{i}}+e^{V_{j}}} \\
& V_{i}=\beta_{0}+\beta_{1} x_{1}+\ldots+\beta_{k} x_{k} .
\end{aligned}
$$

Where $U_{i}$ is utility for crash type $\mathrm{I} ; V_{i}$ is deterministic component of utility for crash type $i ; \varepsilon_{i}$ is stochastic component of utility error for crash type $i ; P_{i}$ is occurrence probability for crash type $i ; \varepsilon^{*}$ is difference in stochastic components of utility error between crash types $i$ and $j ; x_{k}$ is the independent variable $k$ for crash.

In logit models, the maximum likelihood method is used to estimate the coefficients in the utility function. For this estimate, the natural logarithm was taken from the likelihood function [25]. The probability function is shown in Eq. (3), which is based on the cumulative function of stochastic error values. The likelihood ratio ( $\rho^{2}$ was used for fitting the model. This indicator compares the estimated model with a model whose coefficients are all zero. The indicator range is between 0 and 1 . If it is closer to 1 , estimation is better [24]. Eq. (4) shows this indicator.

$$
L(\beta)=\prod_{n=1}^{N} \prod_{i \in c}\left(P_{i n}\right)^{\varphi_{i n}}, \quad L L(\beta)=\prod_{n=1}^{N} \prod_{i \in c} \varphi_{i n} \cdot \operatorname{Ln} P_{i n},
$$

$\rho^{2}=1-\frac{\operatorname{LL}(\widehat{\beta})}{\operatorname{LL}(0)}$

Where $N$ is number of crashes; $i$ is crash type in $C$ set; $\varphi_{i n}$ is binary variable (if crash $n$ with crash type $i$ happen, the binary variable is 1 , otherwise it is 0 ).

Also, the model can be evaluated based on statistical hypothesis of zero coefficients. The parameter $\vartheta$ has a chisquare distribution, and if this parameter is greater than the critical value of the chi-square test, the null hypothesis is rejected (Eq. (5)) [25].

$$
\vartheta=-2(L L(0)-L L \widehat{(\beta)}) \text {. }
$$

\section{Modeling and results}

Due to two possible outcomes, binary logit model has been used in this study. NLogit 5 software was selected for crash data analysis. Also, the backward format procedure was used to acquire the final model. In the first step of this procedure, all variables were entered into the model. In the next step, the variables with lower significance were excluded from the model. The criterion for variable significance is a p-value lower than 0.05 .

Soil and asphalt road shoulder variables were not statistically significant; they were converted together with road shoulder width variable to discrete variable in order to obtain enough significance. This discrete variable shows that the threshold value of the road shoulder is $0.5 \mathrm{~m}$. The numbers of crashes on roads with shoulder width lower and higher than $0.5 \mathrm{~m}$ are 4225 and 4384 crashes respectively.

The final model contains one dependent variable and six independent variables. The p-values of all the variables were lower than 0.05 in the final model. The null hypothesis of variable coefficients was rejected, and the likelihood ratio was 0.0116 . Table 3 shows the final model.

The obtained coefficient of -0.312 for highway class variable illustrates that the probability of rollover crashes decreases in Class I highway. This result may be due to the characteristics of Class I highway, such as road width, pavement quality, etc. This result can be justified with effect of traffic volume. Because of the high population in origin and destination of highways with Class I, traffic volume is more than Class II highway.

The obtained coefficient of 0.221 for the road shoulder width variable shows that the probability of rollover crashes increases on roads with shoulder width less than $0.5 \mathrm{~m}$. This result may be due to the lack of vehicle control on low shoulder-width roads. 
The rainy variable obtained a coefficient of 0.731 in the final model. This coefficient is more than other coefficients and shows that the probability of rollover crashes increases in rainy weather. This is maybe due to the slippery condition of the road in rainy weather.

The snowy variable obtained coefficient of 0.303 , which shows that the probability of rollover crashes increases in snowy weather. This coefficient is less than that of rainy variable and that drivers perhaps are with more caution in snowy weather than in rainy weather.

A coefficient of 0.719 was obtained for the foggy variable in the final model, which shows that the probability of rollover crashes increases in foggy weather. This result may be due to the decrease in the driver's sight distance in foggy weather.

The night condition variable coefficient was 0.184 . This coefficient shows that the probability of rollover crashes increases at night time. This may be due to the decrease in the driver's sight distance at night.

Sensitivity analysis is one of the best methods of determining variable variation in a model. It was performed on the six independent variables obtained in the final model. The results illustrate that the probability of rollover crash

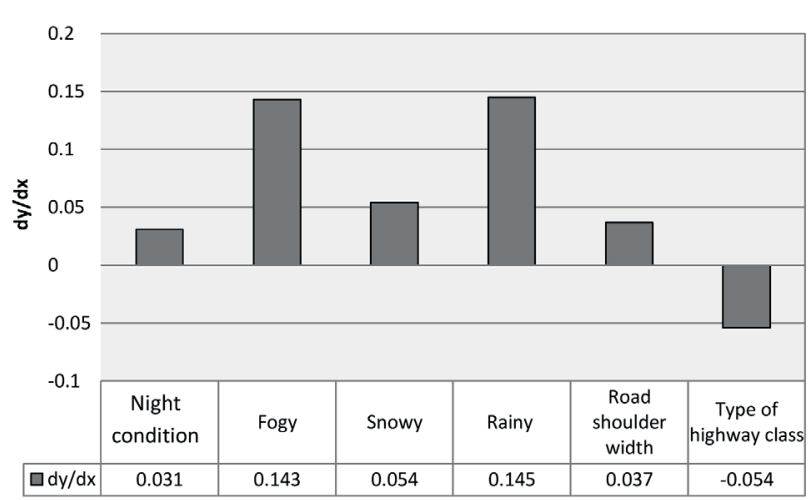

Fig. 2 Sensitivity analysis

occurrence is $21.29 \%$ on the mentioned highway. Table 4 and Fig. 2 show this analysis.

The marginal effect coefficient for highway class variable was -0.054 . This coefficient shows that the probability of occurrence of rollover crashes on a Class I highway is $5.4 \%$ less than that of Class II highway.

The marginal effect coefficient for road shoulder width variable was 0.037 . This coefficient shows that the probability of occurrence of rollover crashes on a road with shoulder width of less than $0.5 \mathrm{~m}$ is $3.7 \%$ more compared with a road with shoulder width of more than $0.5 \mathrm{~m}$.

Table 3 Final model

\begin{tabular}{|c|c|c|c|c|c|c|}
\hline \multicolumn{7}{|c|}{ Dependent variable (Crash type) } \\
\hline \multirow{2}{*}{$\frac{\text { Variable }}{\text { Highway class }}$} & \multirow{2}{*}{$\frac{\text { Coefficient }}{-0.312}$} & \multirow{2}{*}{$\frac{\text { Standard error }}{0.055}$} & \multirow{2}{*}{$\frac{Z}{-5.60}$} & \multirow{2}{*}{$\frac{P>|Z|}{0.000}$} & \multicolumn{2}{|c|}{$95 \%$ Confidence interva } \\
\hline & & & & & -0.421 & -0.203 \\
\hline Road shoulder width $^{\mathrm{a}}$ & 0.221 & 0.053 & 4.12 & 0.000 & 0.116 & 0.326 \\
\hline Rainy & 0.731 & 0.135 & 5.38 & 0.000 & 0.464 & 0.997 \\
\hline Snowy & 0.303 & 0.125 & 2.41 & 0.016 & 0.057 & 0.550 \\
\hline Foggy & 0.719 & 0.248 & 2.89 & 0.004 & 0.231 & 1.206 \\
\hline Night condition & 0.184 & 0.057 & 3.22 & 0.001 & 0.072 & 0.297 \\
\hline \multirow[t]{3}{*}{ Constant } & -1.296 & 0.058 & -22.29 & 0.000 & -1.410 & -1.182 \\
\hline & \multicolumn{2}{|c|}{$\vartheta=-2(L L(0)-L L(\widehat{\beta}))=104.29$} & \multicolumn{3}{|c|}{ Prob $>$ chi $2=0$} & \\
\hline & \multicolumn{2}{|c|}{$\vartheta=-2(L L(0)-L L(\widehat{\beta}))=104.29$} & Prob $>$ chi $2=0$ & & \multicolumn{2}{|c|}{ rejected null hypothesis } \\
\hline
\end{tabular}

a discrete variable of road shoulder width showing that the boundary of the road shoulder is $0.5 \mathrm{~m}$.

Table 4 Sensitivity analysis on probability of rollover crash

\begin{tabular}{|c|c|c|c|c|c|c|}
\hline \multirow{3}{*}{$\frac{\text { Variable }}{\text { Highway class }^{*}}$} & \multicolumn{4}{|c|}{$\begin{array}{c}\text { Marginal effect after logit } \\
Y=\operatorname{Pr}(\text { Rollover } \text { crash })=0.2129\end{array}$} & & \\
\hline & $d y / d x$ & \multirow{2}{*}{$\frac{\text { Standard error }}{0.009}$} & \multirow{2}{*}{$\frac{Z}{-5.45}$} & \multirow{2}{*}{$\frac{P>|Z|}{0.000}$} & \multicolumn{2}{|c|}{$95 \%$ Confidence interva } \\
\hline & -0.054 & & & & -0.073 & -0.034 \\
\hline Road shoulder width* & 0.037 & 0.009 & 4.13 & 0.000 & 0.019 & 0.054 \\
\hline Rainy* $^{*}$ & 0.145 & 0.031 & 4.72 & 0.000 & 0.085 & 0.205 \\
\hline Snowy* & 0.054 & 0.024 & 2.25 & 0.024 & 0.007 & 0.102 \\
\hline Foggy ${ }^{*}$ & 0.143 & 0.056 & 2.53 & 0.011 & 0.032 & 0.255 \\
\hline Night condition* & 0.031 & 0.010 & 3.15 & 0.002 & 0.011 & 0.051 \\
\hline
\end{tabular}

${ }^{*} d y / d x$ for discrete change of dummy variable from 0 to 1 
The rainy variable marginal effect coefficient was 0.145 . This coefficient illustrates that the probability of occurrence of rollover crashes in rainy weather condition is $14.5 \%$ compared with than other weather conditions.

The snowy variable marginal effect coefficient was 0.054 . This coefficient shows that the probability of occurrence of rollover crashes in snowy weather condition is $5.4 \%$ compared with than other weather conditions.

The foggy variable marginal effect coefficient was 0.143 . This coefficient shows that the probability of occurrence of rollover crashes in foggy weather condition is $14.3 \%$ compared with than other weather conditions.

The marginal effect coefficient for night condition variable was 0.031 . This coefficient shows that the probability of the occurrence of rollover crashes in night condition is $3.1 \%$ compared with than other conditions.

Results of the study conducted by Gross and Jovanis [17], indicate that crashes decrease as shoulder width increases and result of our study indicate that rollover crashes decrease as shoulder width increases.

Result of Zegeer and Deacon [11] study indicates that larger accident rates are exhibited on unstabilized shoulders (loose gravel, crushed stone, raw earth, or turf) than on stabilized (e.g., tar plus gravel) or paved (e.g., bituminous or concrete) shoulders but while result of our study indicates that the type of the shoulder is not s significant variable in rollover crashes, in other words, asphalt road shoulder or soil road shoulder with adequate width does not have a significant effects on rollover crash occurrence. Almost like the results of our study, the result of Zegeer and Deacon study [11] indicate that rates of ROR crashes decrease with increasing shoulder width.

Results of the study conducted by Yazdani and Nassiri [5] showed that severity of multi-vehicle crashes was significantly correlated with rainfall, cold weather and roadside equipment but in current study rainy and foggy variables had the greatest effects on rollover crash occurrence.

\section{References}

[1] Wang, Y.-G., Peng, H., Xiang, W.-S., Pei, Y.-L. "Examining injury severity in left turning crashes at intersections", Periodica Polytechnica Civil Engineering, 55(2), pp. 191-197, 2011. https://doi.org/10.3311/pp.ci.2011-2.11

[2] Ma, Z., Zhao, W., Chien, S. I.-J., Dong, C. "Exploring factors contributing to crash injury severity on rural two-lane highways", Journal of Safety Research, 55, pp. 171-176, 2015.

https://doi.org/10.1016/j.jsr.2015.09.003

\section{Conclusions}

The effect of road shoulder and weather condition on rollover crashes was analyzed in this study. Binary logit was selected for modeling, and the final model variables were highway class, road shoulder width, as well as rainy, snowy, foggy and night conditions.

All of the unfavorable weather conditions achieved the positive coefficients. In other words, all of the bad weather conditions increase the probability of rollover crashes. In these condition rainy and foggy variables, with coefficients of 0.731 and 0.719 respectively, had the greatest effects on rollover crash occurrence. Therefore, drivers should be more cautiously in rainy and fogy weathers.

Coefficient of highway types is minus in final model. This means that probability of rollover crashes in highways with Class II is more than Class I. It can be concluded that the drivers fatigue and drowsiness in Class II highways are more than Class I highways. This reason can increase the probability of run-off the road as rollover crashes.

Type of the shoulder is not significant variable in final model but the shoulder width has a positive coefficient. This result indicates that asphalt road shoulder or soil road shoulder with adequate width can be good warning before the run-off the road. But the shoulder types are not effective alone in rollover crashes.

The road shoulder width and night condition, with coefficients of 0.221 and 0.184 respectively, had the least effects on rollover crash occurrence. Sensitivity analysis was performed on the model variables, and the results show that the probability of rollover crash occurrence is $21.29 \%$ on the mentioned highway. Also, this analysis showed variable variation.

[3] Wu, Q., Zhang, G., Zhu, X., Liu, X. C., Tarefder, R. "Analysis of driver injury severity in single-vehicle crashes on rural and urban roadways", Accident Analysis \& Prevention, 94, pp. 35-45, 2016. https://doi.org/10.1016/j.aap.2016.03.026

[4] Rassafi, A. A., Yazdani, M., Shirini, B. "Cross Sectional Crash Severity Analysis Among Various Vehicle Driver Characteristics", Civil Engineering Journal, 4(9), pp. 2143-2154, 2018. https://doi.org/10.28991/cej-03091146 
[5] Yazdani, M., Nassiri, H. "The effect of weather on the severity of multi-vehicle crashes: a case study of Iran", Proceedings of the Institution of Civil Engineers-Transport, 2018.

https://doi.org/10.1680/jtran.18.00080

[6] Jafari Anarkooli, A., Hadji Hosseinlou, M. "Analysis of the injury severity of crashes by considering different lighting conditions on two-lane rural roads", Journal of Safety Research, 56, pp. 57-65, 2016.

https://doi.org/10.1016/j.jsr.2015.12.003

[7] Schneider, W. H., Savolainen, P. T., Zimmerman, K. "Driver Injury Severity Resulting from Single-Vehicle Crashes along Horizontal Curves on Rural Two-Lane Highways", Transportation Research Record: Journal of the Transportation Research Board, 2102(1), pp. 85-92, 2009.

https://doi.org/10.3141/2102-11

[8] Chen, C., Zhang, G., Huang, H., Wang, J., Tarefder, R. A. "Examining driver injury severity outcomes in rural non-interstate roadway crashes using a hierarchical ordered logit model", Accident Analysis \& Prevention, 96, pp. 79-87, 2016. https://doi.org/10.1016/j.aap.2016.06.015

[9] Young, R. K., Liesman, J. "Estimating the relationship between measured wind speed and overturning truck crashes using a binary logit model", Accident Analysis \& Prevention, 39(3), pp. 574-580, 2007.

https://doi.org/10.1016/j.aap.2006.10.002

[10] Farmer, C. M., Lund, A. K. "Rollover risk of cars and light trucks after accounting for driver and environmental factors", Accident Analysis \& Prevention, 34(2), pp. 163-173, 2002. https://doi.org/10.1016/S0001-4575(01)00010-0

[11] Zegeer, C. V., Deacon, J. A. "Effect of Lane Width, Shoulder Width, and Shoulder Type on Highway Safety", Transportation Research Board, Washington, DC, USA, Rep. 6, 1987. [online] Available at: https://trid.trb.org/view/302636 [Accessed: 01 September 2019]

[12] Harwood, D. W., Council, F. M., Hauer, E., Hughes, W. E., Vogt, A. "Prediction of the expected safety performance of rural two-lane highways", Federal Highway Administration, McLean, VA, USA, Rep. FHWA-RD-99-207, 2000. [online] Available at: https:// www.fhwa.dot.gov/publications/research/safety/99207/index.cfm [Accessed: 01 September 2019]

[13] Potts, I. B., Harwood, D. W., Richard, K. R. "Relationship of Lane Width to Safety on Urban and Suburban Arterials", Transportation Research Record: Journal of the Transportation Research Board 2023(1), pp. 63-82, 2007. https://doi.org/10.3141/2023-08

[14] Lee, C., Abdel-Aty, M., Park, J., Wang, J.-H. "Development of crash modification factors for changing lane width on roadway segments using generalized nonlinear models", Accident Analysis \& Prevention 76, pp. 83-91, 2015. https://doi.org/10.1016/j.aap.2015.01.007
[15] Zegeer, C. V., Deen, R. C., Mayes, J. G. "The Effect of Lane and Shoulder Widths on Accident Reductions on Rural, Two-Lane Roads", Kentucky Transportation Center, Lexington, KY, USA, Rep. 561, 1980.

https://doi.org/10.13023/KTC.RR.1980.561

[16] Zegeer, C. V., Hummer, J., Reinfurt, D., Herf, L., Hunter, W. "Safety effects of cross-section design for two-lane", Federal Highway Administration, McLean, VA, USA, Rep. FHWA-RD-87/008, 1987. [online] Available at: https://trid.trb.org/view/274947 [Accessed: 01 September 2019]

[17] Gross, F., Jovanis, P. P. "Estimation of the Safety Effectiveness of Lane and Shoulder Width: Case-Control Approach", Journal of Transportation Engineering, 133(6), pp. 362-369, 2007. https://doi.org/10.1061/(ASCE)0733-947X(2007)133:6(362)

[18] Gross, F., Jovanis, P. P. "Estimation of Safety Effectiveness of Changes in Shoulder Width with Case Control and Cohort Methods", Transportation Research Record: Journal of the Transportation Research Board, 2019(1), pp. 237-245, 2007. https://doi.org/10.3141/2019-28

[19] Gross, F., Donnell, E. T. "Case-control and cross-sectional methods for estimating crash modification factors: Comparisons from roadway lighting and lane and shoulder width safety effect studies", Journal of Safety Research, 42(2), pp. 117-129, 2011. https://doi.org/10.1016/j.jsr.2011.03.003

[20] Wood, J. S., Gooch, J. P., Donnell, E. T. "Estimating the safety effects of lane widths on urban streets in Nebraska using the propensity scores-potential outcomes framework", Accident Analysis \& Prevention, 82, pp. 180-191, 2015. https://doi.org/10.1016/j.aap.2015.06.002

[21] Roque, C., Moura, F., Cardoso, J. L. "Detecting unforgiving roadside contributors through the severity analysis of ran-off-road crashes", Accident Analysis \& Prevention, 80, pp. 262-273, 2015. https://doi.org/10.1016/j.aap.2015.02.012

[22] Roy, U., Dissanayake, S. "Comparison of factors associated with run-off-road and non-run-off-road crashes in Kansas", Journal of the Transportation Research Forum, 50(2), pp. 60-86, 2012.

[23] Wu, Q., Zhang, G., Chen, C., Tarefder, R., Wang, H., Wei, H. "Heterogeneous impacts of gender-interpreted contributing factors on driver injury severities in single-vehicle rollover crashes", Accident Analysis \& Prevention, 94, pp. 28-34, 2016. https://doi.org/10.1016/j.aap.2016.04.005

[24] Kenneth, T. "Discrete choice methods with simulation", 1st ed. Cambridge University Press, Cambridge, UK, 2003. [online] Available at: https://eml.berkeley.edu/books/choice2.html [Accessed: 01 September 2019]

[25] Kenneth, T. "Discrete choice methods with simulation", University of California, Berkeley, CA, USA, 2002. [online] Available at: https://eml.berkeley.edu/books/train1201.pdf [Accessed: 01 September 2019] 